\title{
Prognostic significance of c-Met in breast cancer: a meta-analysis of 6010 cases
}

Shunchao Yan ${ }^{1 *}$, Xin Jiao ${ }^{2}$, Huawei Zou ${ }^{1}$ and Kai Li ${ }^{1}$

\begin{abstract}
Background: The prognostic value of c-Met in breast cancer remains controversial. A meta-analysis of the impact of c-Met in breast cancer was performed by searching published data.

Methods: Published studies analyzing overall survival (OS) or relapse free survival (RFS) according to c-Met expression were searched. The principal outcome measures were hazard ratios (HRs) for RFS or OS according to c-Met expression. Combined HRs were calculated using fixed-or random- effects models according to the heterogeneity.

Results: Twenty-one studies involving 6,010 patients met our selection criteria. The impact of c-Met on RFS and OS was investigated in 12 and 17 studies, respectively. The meta-analysis results showed that c-Met overexpression significantly predicted poor RFS and OS in unselected breast cancer. Subgroup analysis indicated that c-Met overexpression was correlated with poor RFS and OS in Western patients, but was not associated with RFS or OS in Asian patients. C-Met was associated with poor OS in lymph node negative breast cancer and with poor RFS in hormone-receptor positive and triple negative breast cancer, but was not associated with prognosis in human epidermal growth factor receptor (HER)-2 positive breast cancer.
\end{abstract}

Conclusions: C-Met overexpression is an adverse prognostic marker in breast cancer, except among Asian and HER-2 positive patients.

Virtual slides: The virtual slide(s) for this article can be found here: http://www.diagnosticpathology.diagnomx.eu/vs/ 1869780799156041

Keywords: c-Met, Breast cancer, Meta-analysis, Prognosis

\section{Background}

Breast cancer is the most common cancer among women worldwide [1]. The clinical application of targeted therapies, such as tamoxifen and trastuzumab, has decreased the mortality of breast cancer in recent years. However, epidemiological studies show that more than 400,000 patients worldwide die from breast cancer each year [2]. Breast cancer is a heterogeneous disease that has been classified into five molecular subtypes: luminal A, luminal B, human epidermal growth factor receptor-2 (HER-2) overexpressing, basal-like, and normal-like [3]. Current therapeutic regimens for breast cancer are designed according to clinical pathological factors and molecular typing. However, patients with the same clinical

\footnotetext{
* Correspondence: yanshunchao666@163.com

'Department of Oncology, Shengjing Hospital of China Medical University, Shenyang 110022, China

Full list of author information is available at the end of the article
}

stage and molecular type often display markedly different treatment responses and overall outcomes, which lead to treatment failure [4-7]. Therefore, the identification of new prognostic factors and potential therapeutic targets is necessary to improve individual treatment strategies.

The tyrosine kinase c-Met, a key regulator of invasive growth, is overexpressed in certain aggressive cancer cells [8]. c-Met, also called MET and hepatocyte growth factor receptor (HGFR), is a plasma membrane protein that transduces signals from the extracellular matrix to the cytoplasm and is activated by binding to HGF [9]. c-Met is involved in uncontrolled survival, growth, angiogenesis and metastasis of cancer cells [10]. Crizotinib, a dual tyrosine kinase inhibitor of ALK and c-Met kinases, has shown promising results in the treatment of lung adenocarcinoma [11]. Tivantinib, a c-Met inhibitor is being tested in patients with MET-high hepatocellular carcinoma in an ongoing Phase III clinical trial [12]. c-Met was 
shown to be involved in the development of herceptin and endocrine therapy resistance in breast cancer [13, 14]. However, no evidence-based clinical data are available for c-Met inhibitors in breast cancer treatment. Despite the fact that the prognostic role of c-Met in breast cancer has been discussed since the 1990s [15, 16], there is no consensus on its impact. Some studies suggest that c-Met is a stronger prognostic indicator of poor prognosis than traditional markers such as Her2/neu and epidermal growth factor receptor (EGFR) [17-19], whereas others show no statistically significant relation between c-Met and prognosis in breast cancer [20,21]. In recent years, c-Met was reported to be associated with favorable prognosis in breast cancer patients [22, 23]. Therefore, systematic studies are necessary to obtain high level evidence-based results of the prognostic value of c-Met for the identification of patients who would benefit from c-Met targeted therapy and to guide future clinical trials.

In the present study, we enrolled and combined all eligible published studies analyzing the relationship between c-Met expression and relapse free survival (RFS) or overall survival (OS) in breast cancer to clarify the relationship between c-Met expression and prognosis in breast cancer. c-Met plays a critical role in early-stage invasion of cancer cells [24], and crosstalk of c-Met signaling pathways with estrogen receptor (ER) and HER-2 signaling pathways has been reported $[13,25]$. To validate the prognostic role of c-Met in different subtypes breast cancer, we performed a subgroup analysis in lymph node negative and different molecular subtypes of breast cancer.

\section{Methods}

\section{Search strategy}

We searched the electronic databases PubMed, Embase, and the Chinese Biomedical Literature database (CBM) (last search updated in January 1, 2015) by using the keywords "breast cancer", "hepatocyte growth factor receptor", "HGFR", "c-Met", and "prognosis". The titles and abstracts of the studies were firstly scanned to exclude all irrelevant papers. Then, the final inclusion of studies was determined by reading the full text of the remaining articles. The citation lists of all retrieved articles were scanned to identify other potentially relevant reports.

\section{Selection criteria}

The search results were screened according to specific inclusion and exclusion criteria as follows. Inclusion criteria: (1) research limited to human primary breast cancer; (2) the study was published in English or Chinese; (3) inclusion of female patients; (4) evaluation of survival information, such as RFS, OS, according to c-Met expression; (5) the study provided the hazard ratios (HRs) and $95 \%$ confidence intervals (CIs), or data that could be used to calculate the HRs and $95 \%$ CIs, or KaplanMeier survival curves that provided sufficient data to extract HRs and 95 \% CIs; (6) peer-reviewed and published original articles. Exclusion criteria: (1) no data on survival, or inability to calculate the hazard ratios of RFS and OS based on the data provided; (2) letters to editor, reviews and articles published in a book. If patients were enrolled from the same institutions during the same period, the most recently published data were included in the study.

\section{Data extraction}

Two reviewers (Yan SC and Jiao X) performed the search and assessed the studies independently, and the inclusion of a study was decided by consensus. The following items were recorded from each study: the first author's name, year of publication, language, cohort size, assessment methods of c-Met expression, type of patients, hazard ratio (HR) of OS and/or RFS. The studies were assessed for quality using REMARK (reporting recommendations for tumor MARKer prognostic studies) [26], and the definitions of the 18 items for reporting study quality provided by Chen et al. [27].

\section{Statistical analysis}

HRs with $95 \%$ CIs were combined to determine the effective value. If data on HRs and $95 \%$ CIs were not provided directly, the published data and Kaplan-Meier survival curves were used to calculate the HR according to the methods described by Parmaret et al. [28] and Tierney et al. [29]. By convention, an observed HR $>1$ implied a worse survival for the group with c-Met overexpression. The $X^{2}$-square test was used to assess heterogeneity. A $P$-value $<0.05$ was considered significant. If the test of heterogeneity was significant, a combined HR was calculated using the random-effects model; otherwise, the fixed-effects model was used. Engauge Digitizer version 2.11 (free software downloaded from http://sourceforge.net) was used to extract data from Kaplan-Meier curves. Data combining was performed using RevMan version 5.2 (free software downloaded from http:// www.cochrane.org). Begg's tests were used to assess publication bias. Probable significant publication bias was considered at $P<0.05$. In cases of publication bias, the combined estimate was recalculated after imputation from the asymmetry of the funnel plot of the number of "missing" studies, a method known as "trim and fill". Begg tests and "trim and fill" were performed using StataSE12.0 (Stata Corp LP, College Station, Texas, USA).

\section{Results}

\section{Description of studies}

As shown in Fig 1, 544 articles were identified, of which 512 were excluded after screening titles and abstracts 


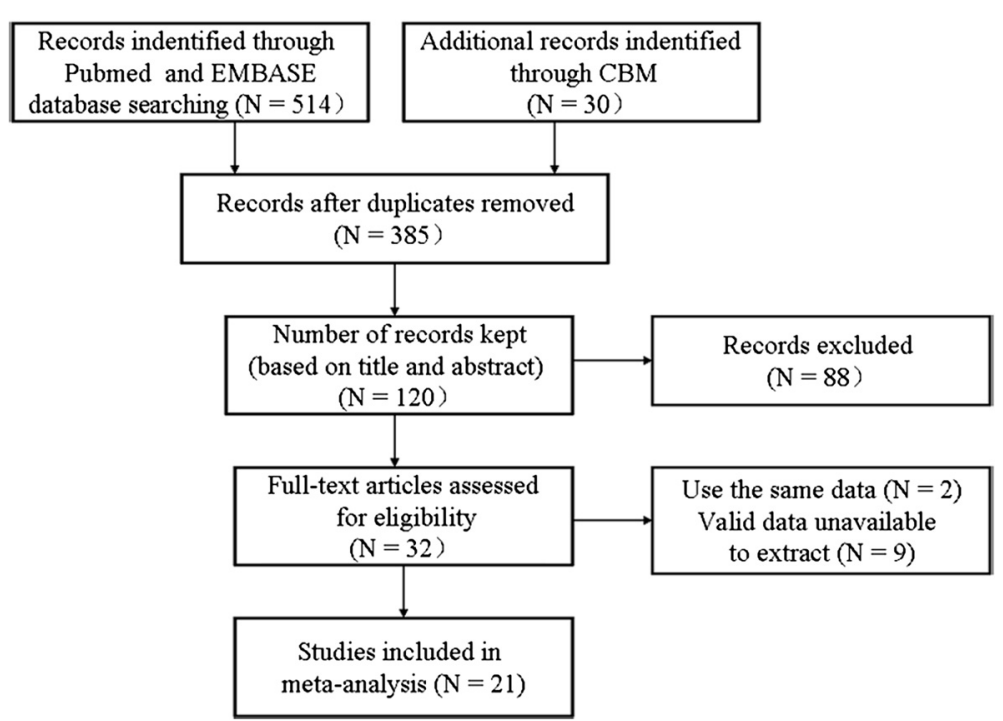

Fig. 1 Brief flow chart. $N$ = number of studies; $C B M=$ Chinese Biomedical Literature database

because they were irrelevant to this study. Three studies were performed in the same institution during the same period; therefore, the most recent study was included and the remaining two were excluded. Nine articles did not provide HRs and the survival data was not sufficient to calculate HRs (validated data unavailable for extraction). Finally, there were 21 eligible studies published between 1991 and 2014 that satisfied the criteria for our meta-analysis [16-23, 30-42]. Five methods were used for the assessment of c-Met expression in breast cancer specimens as follows: immunohistochemistry (IHC), real-time quantitative PCR (RT-PCR), reverse phase protein lysate microarray (RPPA), fluorescence in situ hybridization (FISH), and molecular inversion probes (MIP). All of the 21 eligible studies were retrospective. Table 1 and Table 2 summarize the characteristics of these studies. The number of patients ranged from 33 to 1002 , and the total number of patients analyzed was 6010. Most of the patients included had stage I-IIIa disease and had undergone radical surgery, except one study that included patients with metastatic breast cancer (132 patients) [36].

\section{Impact of c-Met on the RFS and OS of unselected breast cancer}

RFS was analyzed in 12 studies and in a total of 3570 cases. The results showed significant between-study heterogeneity $\left(P=0.02, \mathrm{I}^{2}=50 \%\right)$, and a random-effects model was used. The combined HR was 1.60 (95\% CI $1.27-2.00 ; P<0.0001$ ) (Fig. 2a), which indicated that $c-$ Met overexpression was associated with a 1.6-fold increased risk of recurrence. The meta-analysis incorporating the five imputed studies using the trim and fill method still showed a statistically significant poor RFS in c-Met overexpressing patients (HR, 1.28, $95 \% \mathrm{CI}$, $1.01-1.63, P=0.043)$. Seventeen studies including 4228 cases were evaluated for the effect of c-Met overexpression on OS (Fig. 2b). A random-effects model was used to combine HRs because of the heterogeneity among the studies $\left(P=0.0005 ; \mathrm{I}^{2}=61 \%\right)$. The combined HR was 1.52 (95\% CI 1.15-2.01; $P=0.004$ ), which indicated that c-Met overexpression was associated with a 1.52 -fold increased risk of mortality in breast cancer patients. The trim and fill method omitted one study with a revised estimate of HR and continued to show a statistically significant poor OS in c-Met overexpressing patients (HR, 1.53, 95 \% CI, 1.16-2.03, $P=0.003)$.

\section{Impact of c-Met on the prognosis of Western and Asian patients}

In the subgroup analysis according to ethnicity, the impact of c-Met expression on the RFS of Western patients was evaluated in 8 studies including 2313 cases. No significant heterogeneity was observed $\left(P=0.16, \mathrm{I}^{2}=33 \%\right)$, and the fixed-effects model was used. The results showed that c-Met overexpression was significantly associated with a 1.52-fold increased risk of recurrence $(\mathrm{HR}=$ 1.52, 95 \% CI 1.27-1.83; P<0.00001) (Fig. 3a). The metaanalysis incorporating the four imputed studies using the trim and fill method still showed a statistically significant poor RFS in c-Met overexpressing patients (HR, 1.32, $95 \% \mathrm{CI}, 1.12-1.56, P=0.001)$. The impact of $\mathrm{c}-\mathrm{Met}$ expression on the OS of Western patients was evaluated in 13 studies including 2969 cases. The random-effects model was used because of the observed heterogeneity $\left(P=0.003, \mathrm{I}^{2}=59 \%\right)$. The results of the meta-analysis 
Table 1 Characteristics of the studies included in the meta-analysis

\begin{tabular}{|c|c|c|c|c|c|c|c|c|c|}
\hline First author & Year & Language & $\begin{array}{l}\text { Patients } \\
\text { source }\end{array}$ & $\begin{array}{l}\text { Patients } \\
\text { Number }\end{array}$ & Technique & Type of patients & HR estimation & $\begin{array}{l}\mathrm{HR}(95 \% \mathrm{Cl}) \\
\text { of OS }\end{array}$ & $\begin{array}{l}\mathrm{HR}(95 \% \mathrm{Cl}) \\
\text { of RFS }\end{array}$ \\
\hline Ghoussoub & 1998 & English & USA & 88 & $\mathrm{IHC}$ & $B C$ & Given by author & $3.47(1.22-9.90)$ & NA \\
\hline Camp & 1999 & English & USA & 113 & $\mathrm{IHC}$ & LNN BC & Given by author & $5.05(1.20-21.30)$ & NA \\
\hline Nakopoulou & 2000 & English & Greece & 43 & $\mathrm{IHC}$ & $B C$ & Survival curve & $0.14(0.00-6.41)$ & NA \\
\hline Ocal & 2003 & English & USA & 324 & $\mathrm{IHC}$ & LNN BC & Given by author & $2.04(1.26-3.30)$ & NA \\
\hline Kang & 2003 & English & USA & 330 & $\mathrm{IHC}$ & LNN BC & Given by author & $1.86(1.19-2.91)$ & NA \\
\hline Lengyel & 2005 & English & USA & 40 & $\mathrm{IHC}$ & LNN BC & Given by author & NA & $3.00(1.08-8.30)$ \\
\hline Chen & 2007 & English & Taiwan & 104 & $\mathrm{IHC}$ & Early stage (T1-2NOMO) BC & Given by author & NA & $3.33(1.67-6.65)$ \\
\hline Vendrell & 2008 & English & France & 33 & RTQ-PCR & ER positive $\mathrm{BC}$ & Given by author & $1.08(0.40-2.88)$ & $1.38(0.60-3.21)$ \\
\hline Ponzo & 2009 & English & Canada & 668 & $\mathrm{IHC}$ & LNN BC & Given by author & NA & $1.35(0.87-2.10)$ \\
\hline Liu & 2011 & Chinese & China & 106 & $\mathrm{IHC}$ & $B C$ & Survival curve & $2.41(0.33-17.71)$ & NA \\
\hline Gisterek & 2011 & English & Poland & 302 & $\mathrm{IHC}$ & $\mathrm{BC}$ & Survival curve & $0.45(0.22-0.93)$ & NA \\
\hline $\mathrm{Li}$ & 2012 & Chinese & China & 100 & $\mathrm{IHC}$ & $\mathrm{BC}$ & Survival curve & $1.6(0.15-17.49)$ & $1.59(0.54-4.74)$ \\
\hline Raghav & 2012 & English & USA & 257 & RPPA & $B C$ & Given by author & $2.81(1.19-6.64)$ & $2.06(1.08-3.94)$ \\
\hline Minuti & 2012 & English & Poland & 132 & $\mathrm{FISH}$ & HER-2 positive MBC & Given by author & $1.12(0.65-1.93)$ & NA \\
\hline Gonzalez-Angulo & 2013 & English & USA & 970 & MIP & $B C$ & Given by author & NA & $1.53(0.98-2.38)$ \\
\hline Zagouri & 2013 & English & Austria & 170 & $\mathrm{IHC}$ & TNBC & Given by author & $3.74(1.65-8.46)$ & $3.43(1.65-7.12)$ \\
\hline Ho-Yen & 2014 & English & UK & 1002 & $\mathrm{IHC}$ & $\mathrm{BC}$ & Given by author & $1.85(1.07-3.19)$ & NA \\
\hline Inanc & 2014 & English & Turkey & 97 & $\mathrm{IHC}$ & TNBC & Given by author & $1.16(0.55-2.45)$ & $2.05(0.96-4.37)$ \\
\hline Zagouri & 2014 & English & Austria & 78 & $\mathrm{IHC}$ & ER and HER-2 positive BC & Given by author & $1.32(0.91-1.90)$ & $1.22(0.91-1.63)$ \\
\hline Koh & 2014 & English & Korea & 129 & $\mathrm{IHC}$ & $B C$ & Given by author & $0.37(0.16-0.86)$ & $0.65(0.33-1.26)$ \\
\hline Kim & 2014 & English & Korea & 924 & $\mathrm{IHC}$ & $\mathrm{BC}$ & Given by author & $1.78(1.26-2.51)$ & $1.39(1.08-1.78)$ \\
\hline
\end{tabular}

Note: IHC, immunohistochemistry; RT-PCR, Real-time quantitative PCR; RPRP, Reverse phase protein lysate microarray; FISH, Fluorescence in situ hybridization; MIP, Molecular Inversion Probes; BC, breast cancer; MBC, metatastatic breast cancer; TNBC, triple negative breast cancer; LNN, Lymph Node Negative; OS, over survival; RFS, Relapse-free survival; NA, not available

showed a significantly poor OS in the c-Met overexpression group $(\mathrm{HR}=1.62,95 \% \mathrm{CI} 1.20-2.20, P=0.003)$ (Fig. 3b). Analysis with the trim and fill method omitted one study and continued to show a statistically significant poor RFS in c-Met overexpressing patients (HR, 1.64,
$95 \% \mathrm{CI}, 1.22-2.22, P=0.001)$. Four studies including 1257 cases evaluated the impact of c-Met expression on the RFS of Asian patients, and four studies including 1259 cases evaluated the impact of c-Met expression on the OS of Asian patients. The random-effects model was used

Table 2 Characteristics of the studies according to molecular subtypes

\begin{tabular}{|c|c|c|c|c|c|c|c|c|}
\hline First author & Year & $\begin{array}{l}\text { Patients } \\
\text { Number }\end{array}$ & $\begin{array}{l}\text { Patient } \\
\text { source }\end{array}$ & Technique & Type of patients & HR estimation & $\begin{array}{l}\mathrm{HR}(95 \% \mathrm{Cl}) \\
\text { of OS }\end{array}$ & $\begin{array}{l}\text { HR( }(95 \% \mathrm{Cl}) \\
\text { of RFS }\end{array}$ \\
\hline Vendrell & 2008 & 33 & France & PCR & ER positive $B C$ & Given by author & $1.08(0.40-2.88)$ & $1.38(0.60-3.21)$ \\
\hline \multirow[t]{2}{*}{ Ponzo } & 2009 & 60 & Canada & $\mathrm{IHC}$ & Basal-like BC & Given by author & NA & $3.02(0.31-29.30)$ \\
\hline & & 447 & Canada & $\mathrm{IHC}$ & Nonbasal-like BC & Given by author & NA & $1.49(0.86-2.62)$ \\
\hline \multirow[t]{2}{*}{ Raghav } & 2012 & 64 & USA & RPPA & TNBC & Given by author & NA & $2.36(0.86-6.51)$ \\
\hline & & 140 & USA & RPPA & hormone receptor positive $B C$ & Given by author & $8.28(1.10-62.59)$ & $3.44(1.21-9.81)$ \\
\hline \multirow[t]{3}{*}{ Gonzalez-Angulo } & 2013 & 173 & USA & MIP & TNBC & Given by author & NA & $1.33(0.51-3.43)$ \\
\hline & & 583 & USA & MIP & hormone receptor positive $B C$ & Given by author & NA & $1.86(1.07-3.25)$ \\
\hline & & 207 & USA & MIP & HER-2 positive $B C$ & Given by author & NA & $0.92(0.29-2.95)$ \\
\hline Zagouri & 2013 & 170 & Austria & $\mathrm{IHC}$ & TNBC & Given by author & $3.74(1.65-8.46)$ & $3.43(1.65-7.12)$ \\
\hline Zagouri & 2014 & 78 & Austria & $\mathrm{IHC}$ & ER and HER-2 positive BC & Given by author & $1.32(0.91-1.90)$ & $1.22(0.91-1.63)$ \\
\hline Inanc & 2014 & 97 & Turkey & $\mathrm{IHC}$ & TNBC & Given by author & $1.15(0.54-2.44)$ & $2.05(0.96-4.36)$ \\
\hline
\end{tabular}

Note: IHC, immunohistochemistry; RPRP, Reverse phase protein lysate microarray; FISH, Fluorescence in situ hybridization; MIP, Molecular Inversion Probes; BC, breast cancer; TNBC, triple negative breast cancer; OS, over survival; RFS, Relapse-free survival; NA, not available.cpc 


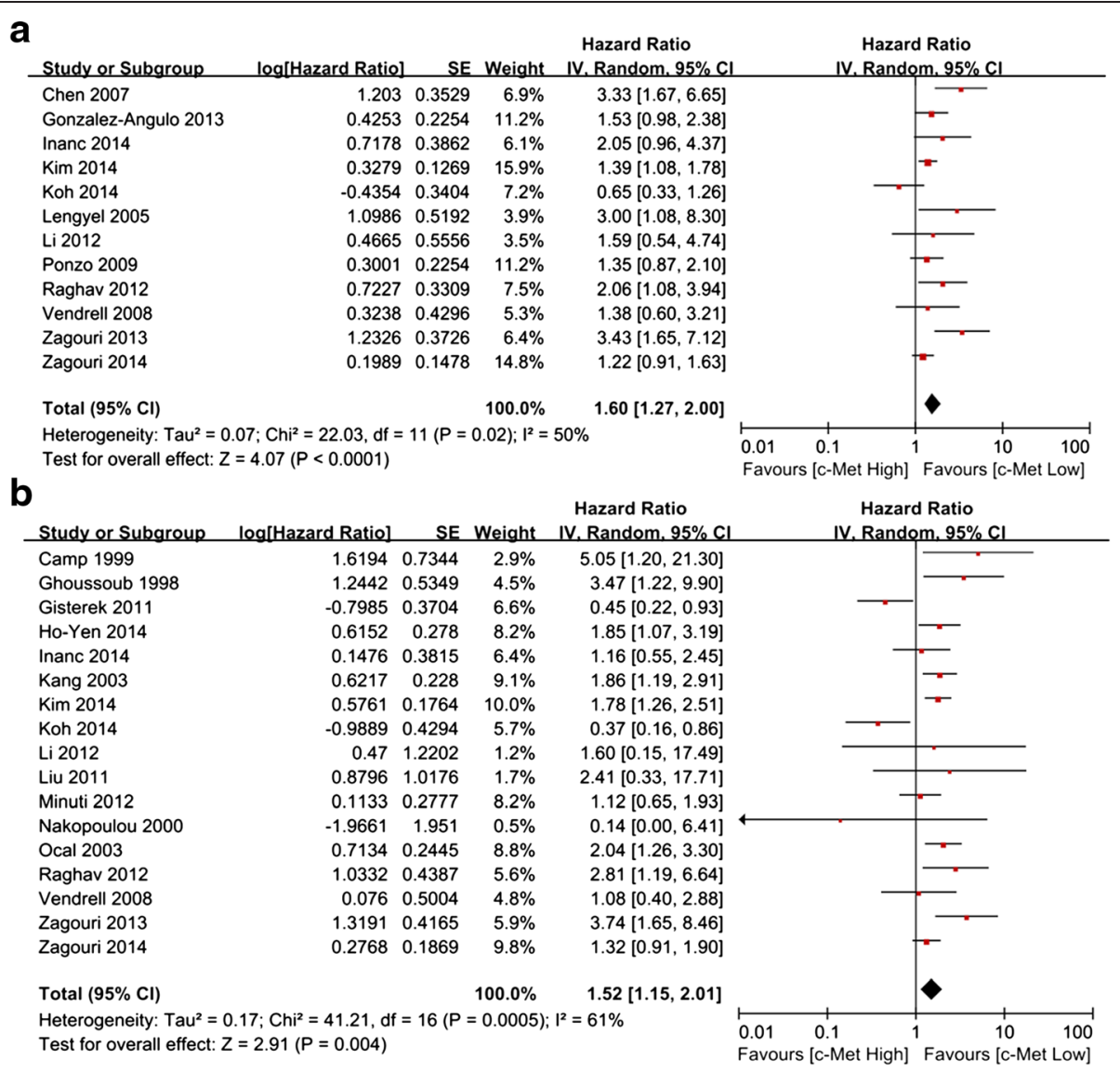

Fig. 2 Forest plot of the hazard ratio (HR) for relapse free survival (RFS) (a) or overall survival (OS) (b) of unselected breast cancer

because of the observed heterogeneity $(P=0.01$ and 0.009 , respectively). Although there was a trend toward increased recurrence (HR 1.45, 95 \% CI 0.80-2.62; $P=0.22$ ) (Fig. 4a) and mortality (HR 1.12, $95 \%$ CI $0.39-3.20 ; P=0.84$ ) (Fig. 4b), it was not statistically significant.

\section{Impact of c-Met on the prognosis of lymph node negative, hormone-receptor positive, HER-2 positive and triple negative breast cancer}

As shown in Table 1, three studies that included lymph node negative patients (767 cases) provided the related OS data. No significant heterogeneity was observed $(P=$ $\left.0.43, \mathrm{I}^{2}=0 \%\right)$, and the fixed-effects model was used. The results showed that c-Met overexpression was associated with a 2.04-fold increased risk of mortality (HR 2.04, 95 \% CI 1.48-2.80; $P<0.0001$ ) (Fig. 5a). As shown in Table 2, four studies included hormone-receptor positive patients (834 cases) and provided the related RFS data. No significant heterogeneity $\left(P=0.20, \mathrm{I}^{2}=36 \%\right)$ was observed among these studies. The fixed-effects model was used, and the results of the meta-analysis showed that c-Met overexpression was associated with a 1.41-fold increased risk of recurrence (HR 1.41, $95 \%$ CI 1.11-1.79, $P=0.005$ ) (Fig. 5b). Two studies included HER-2 positive patients (285 cases) and provided the related RFS data. The fixed-effects model was used $\left(P=0.64, \mathrm{I}^{2}=0 \%\right)$. Although there was a trend toward increased recurrence among patients with c-Met overexpression (HR 1.20, $95 \%$ CI $0.91-1.59, P=0.20$ ) (Fig. 5c), it was not statistically significant. The impact of c-Met expression on RFS in patients with triple negative breast cancer (TNBC) was evaluated in five groups including 564 cases. No significant heterogeneity $\left(P=0.63, \mathrm{I}^{2}=0 \%\right)$ was observed among these studies. The fixed-effects model was used and the result of the meta-analysis showed that c-Met overexpression was significantly associated with a 2.31 -fold increased risk of recurrence (HR 2.31, $95 \%$ CI 1.53-3.48, $P<$ 0.0001) (Fig. 5d).

\section{Publication bias}

Twelve studies evaluating RFS in unselected breast cancer patients were examined by Begg's test. Visual inspection of the funnel plot showed asymmetry $(P=0.029)$ 


\begin{tabular}{|c|c|c|c|c|c|c|c|}
\hline a & astudy or Subgroup & log[Hazard Ratiol & SE & E Weight & $\begin{array}{l}\text { Hazard Ratio } \\
\text { IV.Fixed.95\% Cl }\end{array}$ & $\begin{array}{r}\text { Hazard } \\
\text { IV. Fixed. }\end{array}$ & $\begin{array}{l}\text { Ratio } \\
95 \% \mathrm{Cl}\end{array}$ \\
\hline & Gonzalez-Angulo 2013 & 0.4253 & 30.2254 & $4 \quad 16.8 \%$ & $1.53[0.98,2.38]$ & & $=$ \\
\hline & Inanc 2014 & 0.7178 & $\begin{array}{ll}8 & 0.3862\end{array}$ & $2 \quad 5.7 \%$ & $2.05[0.96,4.37]$ & & - \\
\hline & Lengyel 2005 & 1.0986 & 60.5192 & $2 \quad 3.2 \%$ & $3.00[1.08,8.30]$ & & \\
\hline & Ponzo 2009 & 0.3001 & 10.2254 & $4 \quad 16.8 \%$ & $1.35[0.87,2.10]$ & & $=$ \\
\hline & Raghav 2012 & 0.7227 & 7 0.3309 & $9 \quad 7.8 \%$ & $2.06[1.08,3.94]$ & & 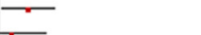 \\
\hline & Vendrell 2008 & 0.3238 & B 0.4296 & $4.6 \%$ & $1.38[0.60,3.21]$ & & - \\
\hline & Zagouri 2013 & 1.2326 & $\begin{array}{ll}6 & 0.3726\end{array}$ & $6 \quad 6.1 \%$ & $3.43[1.65,7.12]$ & & - \\
\hline & Zagouri 2014 & 0.1989 & 90.1478 & $8 \quad 39.0 \%$ & $1.22[0.91,1.63]$ & & $=$ \\
\hline & Total $(95 \% \mathrm{Cl})$ & & & $100.0 \%$ & $1.52[1.27,1.83]$ & & $\bullet$ \\
\hline & $\begin{array}{l}\text { Heterogeneity: } \mathrm{Chi}^{2}=10 \\
\text { Test for overall effect: } Z\end{array}$ & $\begin{array}{l}0.47, \text { df }=7(P=0.16) ; \\
=4.57(P<0.00001)\end{array}$ & ) $1^{2}=33 \%$ & & & $\begin{array}{lll}0.01 & 0.1 & 1 \\
\text { Favours Ic-Met Hiahl }\end{array}$ & $\begin{array}{cc}10 & 100 \\
\text { Favours Ic-Met Lowl }\end{array}$ \\
\hline b & 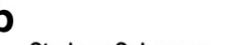 & & & & Hazard Ratio & Hazard & d Ratio \\
\hline & Study or Subgroup & log[Hazard Ratio] & SE $V$ & Weight & IV. Random. $95 \% \mathrm{Cl}$ & IV. Rando & om. $95 \% \mathrm{Cl}$ \\
\hline & Camp 1999 & $1.6194 \mathrm{O}$ & 0.7344 & $3.4 \%$ & $5.05[1.20,21.30]$ & & ב \\
\hline & Ghoussoub 1998 & $1.2442 \mathrm{c}$ & 0.5349 & $5.4 \%$ & $3.47[1.22,9.90]$ & & 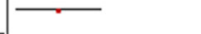 \\
\hline & Gisterek 2011 & -0.79850 & 0.3704 & $8.1 \%$ & $0.45[0.22,0.93]$ & & \\
\hline & Ho-Yen 2014 & 0.6152 & 0.278 & $10.1 \%$ & $1.85[1.07,3.19]$ & & - \\
\hline & Inanc 2014 & 0.14760 & 0.3815 & $7.9 \%$ & $1.16[0.55,2.45]$ & & + \\
\hline & Kang 2003 & 0.6217 & 0.228 & $11.3 \%$ & $1.86[1.19,2.91]$ & & - \\
\hline & Minuti 2012 & 0.11330 & 0.2777 & $10.1 \%$ & $1.12[0.65,1.93]$ & & + \\
\hline & Nakopoulou 2000 & -1.9661 & 1.951 & $0.6 \%$ & $0.14[0.00 .6 .41]$ & & \\
\hline & Ocal 2003 & 0.71340 & 0.2445 & $10.9 \%$ & $2.04[1.26,3.30]$ & & $\rightarrow$ \\
\hline & Raghav 2012 & 1.03320 & 0.4387 & $6.8 \%$ & $2.81[1.19,6.64]$ & & $\rightarrow$ \\
\hline & Vendrell 2008 & 0.0760 & 0.5004 & $5.8 \%$ & $1.08[0.40,2.88]$ & & - \\
\hline & Zagouri 2013 & 1.31910 & 0.4165 & $7.2 \%$ & $3.74[1.65,8.46]$ & & - \\
\hline & Zagouri 2014 & 0.27680 & 0.1869 & $12.3 \%$ & $1.32[0.91,1.90]$ & & - \\
\hline & Total $(95 \% \mathrm{Cl})$ & & & $100.0 \%$ & $1.62[1.20,2.20]$ & & $\bullet$ \\
\hline & $\begin{array}{l}\text { Heterogeneity: } \operatorname{Tau}^{2}=0 \\
\text { Test for overall effect: } Z\end{array}$ & $\begin{array}{l}0.16 ; \mathrm{Chi}^{2}=29.35, \mathrm{df}= \\
Z=3.13(P=0.002)\end{array}$ & $=12(P=$ & $=0.003): 1^{2}$ & $=59 \%$ & $\begin{array}{ll}0.01 & 0.1 \\
\text { Favours [c-Met High] }\end{array}$ & $\begin{array}{|ccc|}1 & 10 & 100 \\
1 & \text { Favours [c-Met Low] }\end{array}$ \\
\hline
\end{tabular}

(Fig. 6a), suggesting publication bias. Sensitivity analysis was performed using the trim and fill method, which conservatively imputes hypothetical negative unpublished studies or omits certain studies to mirror the positive studies that cause funnel plot asymmetry. Five hypothetical studies were imputed and the funnel plot symmetry was created (Fig. 6b). The meta-analysis incorporating the imputed studies still showed a statistically significant poor RFS in c-Met overexpressing patients. Seventeen studies evaluating OS in unselected breast cancer patients were analyzed by Begg's test. Visual inspection of the funnel plot showed asymmetry, although the Begg's test result was not statistically significant $(P=0.105)$ (Fig. 6c). The trim and fill method omitted one study and created a symmetrical funnel plot (Fig. 6d). The general result was not changed. The Western patient subgroup showed similar results as the unselected breast cancer patients. No publication bias was detected in the other subgroup meta-analyses.

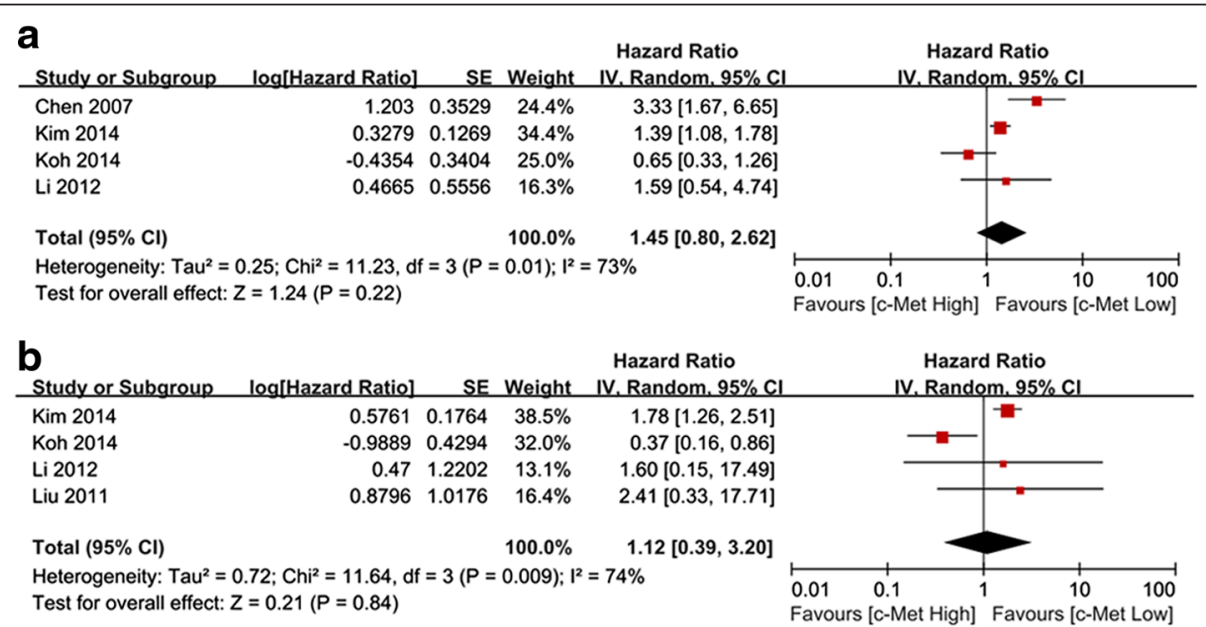

Fig. 4 Forest plot of HR for RFS (a) and OS (b) among Asian patients 


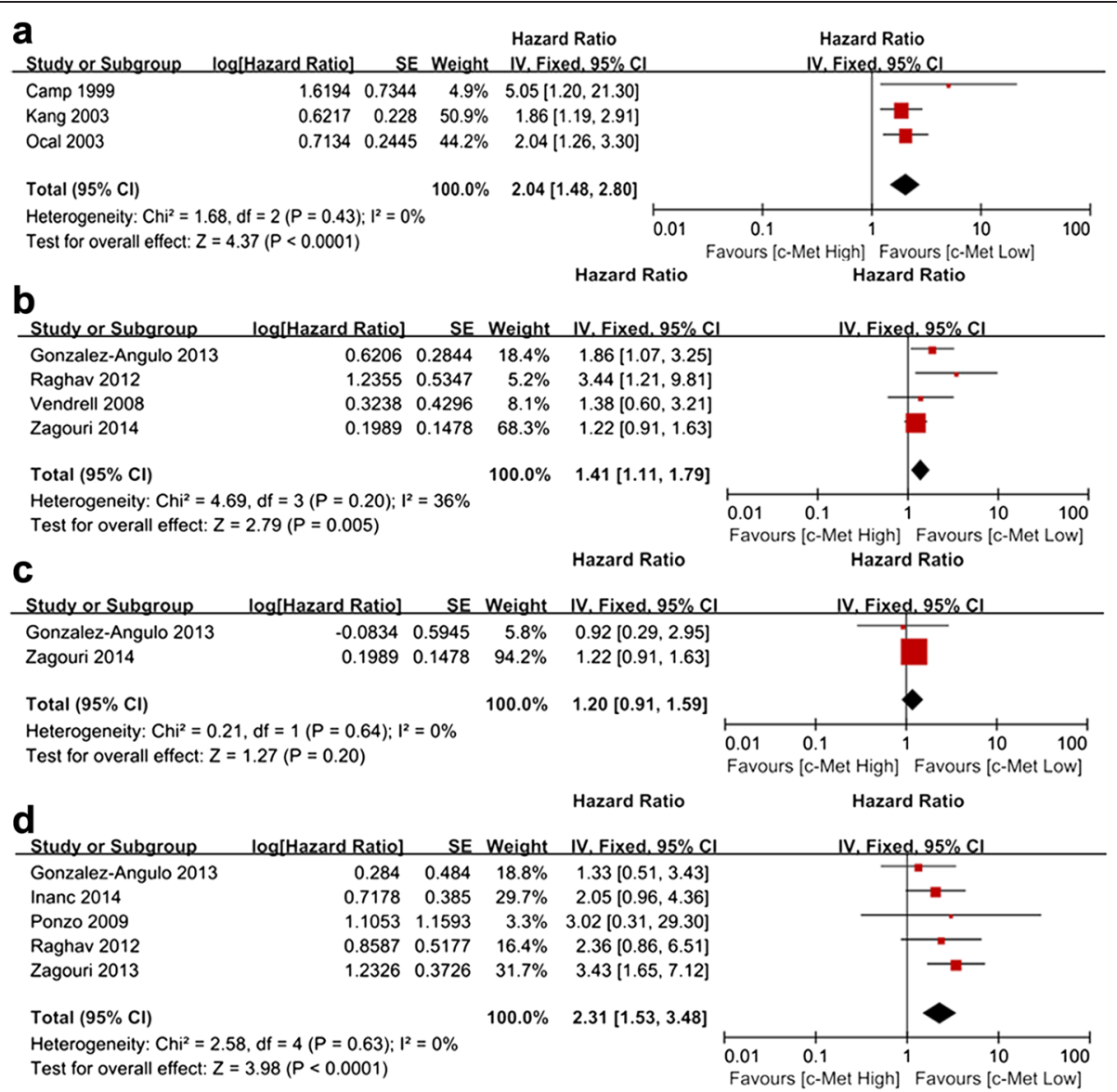

Fig. 5 Forest plot of the HR for OS among lymph node negative (a), hormone-receptor positive (b), HER-2 positive (c) and triple negative breast cancer (d)

\section{Discussion}

In recent years, the development of target-based therapies has improved the prognosis of cancer patients. However, only a subset of patients benefits from the use of specific drugs, and the development of resistance often results in clinical treatment failure. The identification of novel targets is a challenging task for the medical oncologist, and valuable prognostic markers might become potential therapeutic targets in the future. The trasmembrane tyrosine kinase receptor c-Met plays a vital role in cell survival, growth and metastasis [8]. c-Met is overexpressed in a variety of carcinomas and is associated with resistance to herceptin and gefitinib, and it represents an attractive target for antitumor treatment [13, 43]. c-Met overexpression has been reported in 14-53.6 \% of patients with breast cancer $[20,39,40]$. Evidence of the influence of c-Met expression on survival outcomes in breast cancer is inconclusive. In the present study, we analyzed 21 studies published between 1998 and 2014 and comprising a total of 6010 cases. The results of the meta-analysis showed that c-Met overexpression is a statistically significant adverse predictor of RFS and OS in unselected breast cancer. These results provide evidence supporting future trials evaluating the effect of c-Met inhibitors in breast cancer.

Originally, Iressa, a selective EGFR inhibitor, showed promising results among Asian patients, but not in Western populations, suggesting a possible role of ethnic differences between Asian and Western lung cancer patients [44]. The differences in the characteristics of breast cancer between Asian and Western countries have also been discussed for several years [45]. In the present study, we performed a subgroup analysis according to ethnicity. In the Western patient group, there were 8 studies analyzing RFS and 13 studies analyzing OS according to c-Met expression. Our results showed that c-Met is a predictor of poor prognosis (both RFS and OS) in Western patients. In the Asian patient group, four studies analyzing c-Met expression according to OS/RFS were identified. The results showed that there was a trend toward increased recurrence and mortality in c-Met overexpressing patients, although the difference did not reach statistical significance. Further analysis including a larger number of patients and studies is necessary to evaluate the prognostic role of c-Met in Asian 

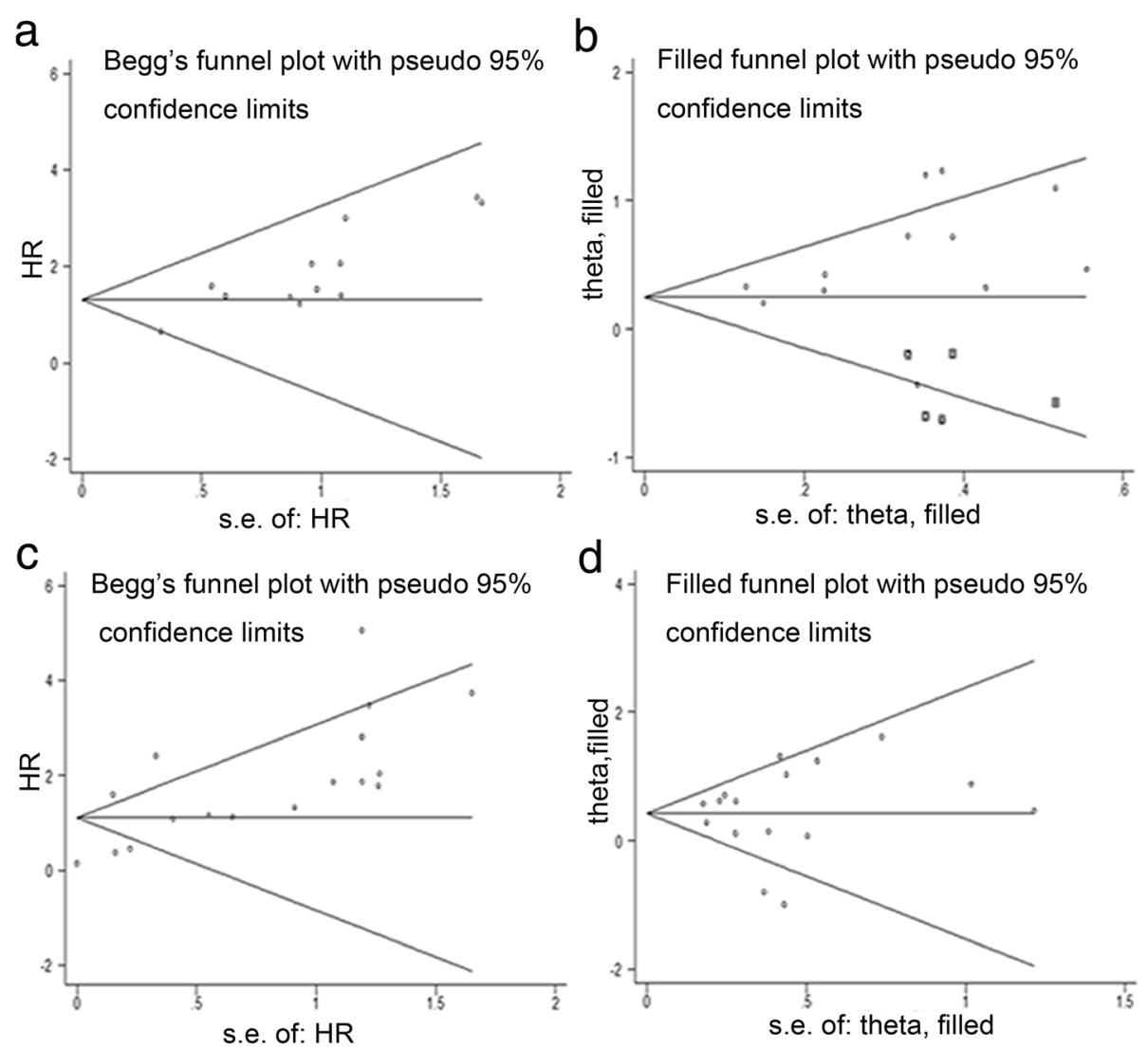

Fig. 6 Funnel plot without and with trim and fill for RFS (a and $\mathbf{b}$ ) and OS (c and $\mathbf{d}$ ) of unselected breast cancer

breast cancer patients, and to determine whether c-Met status has a different influence on the prognosis of Asian and Western breast cancer patients.

Lymph node status is the best indicator of prognosis in breast cancer. Additional makers are necessary to predict prognosis in patients with lymph node negative breast cancer. C-Met expression is higher and more frequently positive in metastatic lymph nodes than in the primary tumor [19]. In the present analysis, three studies provided data on OS in lymph node negative patients. The meta-analysis results showed that c-Met overexpression was associated with a 2.04-fold increased risk of mortality (combined HR 2.04, 95 \% CI 1.48-2.80; $P<$ $0.0001)$ in lymph node negative breast cancer. These results demonstrate that c-Met might act at the early stages of breast cancer, and its expression should be detected on postoperative pathology to predict prognosis and guide the postoperative treatment.

Breast cancer is divided into five molecular subtypes based on the status of ER, PR, HER-2 and Ki67 [3]. In the present study, we performed subgroup analysis according to molecular subtypes. Four studies provided data on RFS in the hormone-receptor positive subgroup. The meta-analysis results showed that c-Met overexpression was associated with a 1.41 -fold increased risk of recurrence (combined HR 1.41, 95 \% CI 1.11-1.79; $P=0.005)$ in the hormone-receptor positive group. Endocrine therapy is the most important systemic treatment for hormone-receptor positive breast cancer at all stages [46]. C-Met and the Ron receptor tyrosine kinase, a member of the c-Met family of receptors, are associated with resistance to breast cancer endocrine therapy in vitro [14, 47]. Overexpression of HER-2 is associated with resistance to endocrine therapy in breast cancer [48]. Zagouri et al. showed that c-Met was not a prognostic factor in ER- and HER2-positive breast carcinomas [20]. In addition, the prognostic value of c-Met was shown to be independent of HER2/neu [19]. Consequently, c-Met might influence the prognosis of hormone-receptor positive patients by mediating resistance to endocrine therapy, especially in the hormone-receptor positive/HER-2 negative subgroup in a Her-2 independent manner. This subgroup is likely to benefit from combined treatment with c-Met inhibitors and estrogen inhibition therapy in the future. However, additional studies are needed to confirm these results.

Functional crosstalk of c-Met with HER-2 has been reported to enhance cell invasion in Madin-Darby canine kidney (MDCK) epithelial cells in vitro [49]. In breast 
cancer cells, this crosstalk is involved in the development of Herceptin resistance in vitro [13]. In the present analysis, two studies provided RFS data in HER-2 positive patients. The meta-analysis results showed that cMet overexpression was associated with poor prognosis, but the findings did not reach statistical significance (combined HR 1.20, $95 \%$ CI 0.91-1.59; $P=0.20$ ). Additionally, Minuti et al. found that c-Met is associated with shorter time to progression (TTP) in HER2-positive metastatic breast cancer [36]. Thus, additional studies are necessary to explore the clinical interaction of c-Met and Her-2.

According to currently available data, TNBC is the most aggressive subtype of breast cancer, and no targeted therapy is currently available [39]. TNBC could be further subclassified into basal-like breast cancer (BLBC) and quintuple-negative breast cancer (QNBC), and cMet is involved in the development of BLBC [33]. Five studies provided RFS data in the TNBC subgroup. The meta-analysis results showed that c-Met overexpression increased recurrence risk by 2.31 -fold in TNBC (combined HR 2.31, 95 \% CI: 1.53-3.48, $P<0.0001$ ), which was the highest risk in this study. The results indicate that c-Met could be a therapeutic target, thereby providing new treatment options for TNBC.

Quality assessment according to REMARK guidelines was performed for all 21 included studies. The studies fulfilled, on average, 14 items (range, 10-18 items) of the guidelines. Sensitivity and sub-group analyses were performed to ensure that the results were reliable and valid. However, our meta-analysis had several limitations. First, the results of sub-analysis were less powerful because the combined HR of some subgroups was calculated on the basis of 2-5 studies with a relative small patient sample size. Second, c-Met was detected by five different methods, although most studies detected c-Met by IHC (excluding the molecular subtype groups). In addition, there were differences in the criteria for c-Met positivity in IHC detection. Third, the funnel plot analysis showed some asymmetry, suggesting the possibility of publication bias in unselected patients and Western patients. The trim and fill sensitivity analysis did not change the general results, suggesting that the results were not influenced by the unpublished negative studies or the small sample size. Additional high-quality data are necessary to draw more reliable conclusions.

\section{Conclusions}

Our comprehensive meta-analysis of all published studies showed that c-Met overexpression is significantly associated with poor survival in breast cancer patients, especially in the TNBC subgroup. In Asian patients and HER-2 positive breast carcinomas, c-Met might not be associated with prognosis.

\section{Competing interests}

The authors declare that they have no competing interests.

\section{Authors' contributions}

All authors participated in the study design. SY performed the literature search, data extraction, statistical analysis and drafted the manuscript. XJ, HZ and $\mathrm{KL}$ participated in data extraction. All authors read and approved the final manuscript.

\section{Acknowledgments}

This research was supported by grants from the National Science Foundation of China (81302313).

\section{Author details}

${ }^{1}$ Department of Oncology, Shengjing Hospital of China Medical University, Shenyang 110022, China. ${ }^{2}$ Department of Respiratory Medicine, Shenyang Chest Hospital, Shenyang 110044, China.

Received: 6 January 2015 Accepted: 12 May 2015

Published online: 06 June 2015

\section{References}

1. Ferlay J, Shin HR, Bray F, Forman D, Mathers C, Parkin DM. Estimates of worldwide burden of cancer in 2008: GLOBOCAN 2008. Int J Cancer. 2010;127:2893-917.

2. Kamangar F, Dores GM, Anderson WF. Patterns of cancer incidence, mortality, and prevalence across five continents: defining priorities to reduce cancer disparities in different geographic regions of the world. J Clin Oncol. 2006;24:2137-50.

3. Yersal O, Barutca S. Biological subtypes of breast cancer. Prognostic and therapeutic implications. World J Clin Oncol. 2014;5:412-24.

4. van 't Veer LJ, Dai H, Van de Vijver MJ, He YD, Hart AA, Mao M, et al. Gene expression profiling predicts clinical outcome of breast cancer. Nature. 2002;415:530-6.

5. Kassam F, Enright K, Dent R, Dranitsaris G, Myers J, Flynn C, et al. Survival outcomes for patients with metastatic triple-negative breast cancer: implications for clinical practice and trial design. Clin Breast Cancer. 2009;9:29-33.

6. Polyak K. Heterogeneity in breast cancer. J Clin Invest. 2011;121:3786-8.

7. Lee HJ, Seo AN, Kim EJ, Jang MH, Suh KJ, Ryu HS, et al. HER2 heterogeneity affects trastuzumab responses and survival in patients with HER2-positive metastatic breast cancer. Am J Clin Pathol. 2014;142:755-66.

8. Boccaccio C, Comoglio PM. Invasive growth: a MET-driven genetic programme for cancer and stem cells. Nat Rev Cancer. 2006;6:637-45.

9. Birchmeier C, Gherardi E. Developmental roles of HGF/SF and its receptor, the c-Met tyrosine kinase. Trends Cell Biol. 1998;8:404-10.

10. Gherardi E, Birchmeier W, Birchmeier C, Vande Woude G. Targeting MET in cancer: rationale and progress. Nat Rev Cancer. 2012;12:89-103.

11. Casaluce F, Sgambato A, Maione P, Rossi A, Ferrara C, Napolitano A, et al. ALK inhibitors: a new targeted therapy in the treatment of advanced NSCLC. Target Oncol. 2013;8:55-67.

12. Rota Caremoli E, Labianca R. Tivantinib: critical review with a focus on hepatocellular carcinoma. Expert Opin Investig Drugs. 2014;23:1563-74.

13. Shattuck DL, Miller JK, Carraway 3rd KL, Sweeney C. Met receptor contributes to trastuzumab resistance of Her 2-overexpressing breast cancer cells. Cancer Res. 2008;68:1471-7.

14. Hiscox S, Jordan NJ, Jiang W, Harper M, McClelland R, Smith C. Chronic exposure to fulvestrant promotes overexpression of the c-Met receptor in breast cancer cells: implications for tumour-stroma interactions. Endocr Relat Cancer. 2006;13:1085-99.

15. Nagy J, Curry GW, Hillan KJ, McKay IC, Mallon E, Purushotham AD, et al. Hepatocyte growth factor/scatter factor expression and c-met in primary breast cancer. Surg Oncol. 1996:5:15-21.

16. Vendrell JA, Robertson KE, Ravel P, Bray SE, Bajard A, Purdie CA, et al. A candidate molecular signature associated with tamoxifen failure in primary breast cancer. Breast Cancer Res. 2008;10:R88.

17. Ghoussoub RA, Dillon DA, D'Aquila T, Rimm EB, Fearon ER, Rimm DL. Expression of c-met is a strong independent prognostic factor in breast carcinoma. Cancer. 1998;82:1513-20.

18. Tolgay Ocal I, Dolled-Filhart M, D'Aquila TG, Camp RL, Rimm DL. Tissue microarray-based studies of patients with lymph node negative breast carcinoma show that met expression is associated with worse outcome but 
is not correlated with epidermal growth factor family receptors. Cancer. 2003:97:1841-8.

19. Lengyel E, Prechtel D, Resau JH, Gauger K, Welk A, Lindemann K, et al. C-Met overexpression in node-positive breast cancer identifies patients with poor clinical outcome independent of Her2/neu. Int J Cancer. 2005;113:678-82.

20. Inanc M, Ozkan M, Karaca H, Berk V, Bozkurt O, Duran AO, et al. Cytokeratin 5/6, c-Met expressions, and PTEN loss prognostic indicators in triplenegative breast cancer. Med Oncol. 2014;31:801.

21. Zagouri F, Brandstetter A, Moussiolis D, Chrysikos D, Dimitrakakis C, Tsigginou $\mathrm{A}$, et al. Low protein expression of MET in ER-positive and HER2positive breast cancer. Anticancer Res. 2014;34:1227-31.

22. Gisterek I, Lata E, Halon A, Matkowski R, Szelachowska J, Biecek P, et al. Prognostic role of c-met expression in breast cancer patients. Rep Pract Oncol Radiother. 2011;16:173-7.

23. Koh YW, Lee HJ, Ahn JH, Lee JW, Gong G. MET expression is associated with disease-specific survival in breast cancer patients in the neoadjuvant setting. Pathol Res Pract. 2014;210:494-500.

24. Zhang YW, Vande Woude GF. HGF/SF-met signaling in the control of branching morphogenesis and invasion. J Cell Biochem. 2003;88:408-17.

25. Hiscox S, Jordan NJ, Jiang W, Harper M, McClelland R, Smith C, et al. Chronic exposure to fulvestrant promotes overexpression of the c-Met receptor in breast cancer cells: implications for tumour-stroma interactions. Endocr Relat Cancer. 2006;13:1085-99.

26. McShane LM, Altman DG, Sauerbrei W, Taube SE, Gion M, Clark GM. REporting recommendations for tumour MARKer prognostic studies (REMARK). Eur J Cancer. 2005;41:1690-6.

27. Chen M, Cai E, Huang J, Yu P, Li K. Prognostic value of vascular endothelial growth factor expression in patients with esophageal cancer: a systematic review and meta-analysis. Cancer Epidemiol Biomarkers Prev. 2012;21:1126-34.

28. Parmar MK, Torri V, Stewart L. Extracting summary statistics to perform meta-analyses of the published literature for survival endpoints. Stat Med. 1998;17:2815-34

29. Tierney JF, Stewart LA, Ghersi D, Burdett S, Sydes MR. Practical methods for incorporating summary time-to-event data into meta-analysis. Trials. 2007:8:16.

30. Nakopoulou L, Gakiopoulou H, Keramopoulos A, Giannopoulou I, Athanassiadou P, Mavrommatis J, et al. c-met tyrosine kinase receptor expression is associated with abnormal beta-catenin expression and favourable prognostic factors in invasive breast carcinoma. Histopathology. 2000;36:313-25.

31. Camp RL, Rimm EB, Rimm DL. Met expression is associated with poor outcome in patients with axillary lymph node negative breast carcinoma. Cancer. 1999:86:2259-65.

32. Kang JY, Dolled-Filhart M, Ocal IT, Singh B, Lin CY, Dickson RB, et al. Tissue microarray analysis of hepatocyte growth factor/Met pathway components reveals a role for Met, matriptase, and hepatocyte growth factor activator inhibitor 1 in the progression of node-negative breast cancer. Cancer Res. 2003:63:1101-5.

33. Chen HH, Su WC, Lin PW, Guo HR, Lee WY. Hypoxia-inducible factor-1alpha correlates with MET and metastasis in node-negative breast cancer. Breast Cancer Res Treat. 2007;103:167-75.

34. Ponzo MG, Lesurf R, Petkiewicz S, O'Malley FP, Pinnaduwage D, Andrulis IL, et al. Met induces mammary tumors with diverse histologies and is associated with poor outcome and human basal breast cancer. Proc Natl Acad Sci U S A. 2009;106:12903-8.

35. Liu T, FENG XH, Ren ZG, Wang JG. Expression of c-Met and its clinical significance in breast cancer. J Surg Concepts Pract. 2011;16:42-4.

36. Minuti G, Cappuzzo F, Duchnowska R, Jassem J, Fabi A, O'Brien T, et al. Increased MET and HGF gene copy numbers are associated with trastuzumab failure in HER2-positive metastatic breast cancer. $\mathrm{Br} J$ Cancer. 2012;107:793-9.

37. Li B, Lu YL, Liu L, Zhao P. Clinicopathological significance of expression of c-Met in invasive breast ductal carcinoma. Chin J Clinicians (Electronic Edition). 2012;6:99-102.

38. Raghav KP, Wang W, Liu S, Chavez-MacGregor M, Meng X, Hortobagyi GN, et al. CMET and phospho-CMET protein levels in breast cancers and survival outcomes. Clin Cancer Res. 2012;18:2269-77.

39. Gonzalez-Angulo AM, Chen H, Karuturi MS, Chavez-MacGregor M, Tsavachidis S, Meric-Bernstam F, et al. Frequency of mesenchymal-epithelial transition factor gene (MET) and the catalytic subunit of phosphoinositide-3-kinase (PIK3CA) copy number elevation and correlation with outcome in patients with early stage breast cancer. Cancer. 2013;119:7-15.
40. Zagouri F, Bago-Horvath Z, Rössler F, Brandstetter A, Bartsch R, Papadimitriou CA, et al. High MET expression is an adverse prognostic factor in patients with triple-negative breast cancer. Br J Cancer. 2013;108:1100-5.

41. Ho-Yen CM, Green AR, Rakha EA, Brentnall AR, Ellis IO, Kermorgant S, et al. C-Met in invasive breast cancer: is there a relationship with the basal-like subtype? Cancer. 2014:120:163-71.

42. Kim YJ, Choi JS, Seo J, Song JY, Lee SE, Kwon MJ, et al. MET is a potential target for use in combination therapy with EGFR inhibition in triplenegative/basal-like breast cancer. Int J Cancer. 2014;134:2424-36

43. Cappuzzo F, Jänne PA, Skokan M, Finocchiaro G, Rossi E, Ligorio C, et al. MET increased gene copy number and primary resistance to gefitinib therapy in non-small-cell lung cancer patients. Ann Oncol. 2009;20:298-304.

44. Zhou W, Christiani DC. East meets West: ethnic differences in epidemiology and clinical behaviors of lung cancer between East Asians and Caucasians. Chin J Cancer. 2011;30:287-92.

45. Leong SP, Shen ZZ, Liu TJ, Agarwal G, Tajima T, Paik NS, et al. Is breast cancer the same disease in Asian and Western countries? World J Surg. 2010;34:2308-24

46. Sainsbury R. The development of endocrine therapy for women with breast cancer. Cancer Treat Rev. 2013;39:507-17.

47. McClaine RJ, Marshall AM, Wagh PK, Waltz SE. Ron receptor tyrosine kinase activation confers resistance to tamoxifen in breast cancer cell lines. Neoplasia. 2010;12:650-8.

48. Dowsett M. Overexpression of HER-2 as a resistance mechanism to hormonal therapy for breast cancer. Endocr Relat Cancer. 2001;8:191-5.

49. Khoury H, Naujokas MA, Zuo D, Sangwan V, Frigault MM, Petkiewicz S, et al. HGF converts ErbB2/Neu epithelial morphogenesis to cell invasion. Mol Biol Cell. 2005;16:550-61.

\section{Submit your next manuscript to BioMed Central and take full advantage of:}

- Convenient online submission

- Thorough peer review

- No space constraints or color figure charges

- Immediate publication on acceptance

- Inclusion in PubMed, CAS, Scopus and Google Scholar

- Research which is freely available for redistribution

Submit your manuscript at www.biomedcentral.com/submit
C BioMed Central 